\title{
Re-evaluation of a Neonatal Mouse Model of Infection With Enterotoxigenic Escherichia coli
}

\section{OPEN ACCESS}

Edited by:

Leonard Peruski,

Centers for Disease Control and Prevention (CDC), United States

Reviewed by:

James Michael Fleckenstein, Washington University in St. Louis,

United States

Eric Cox,

Ghent University, Belgium George P. Munson,

University of Miami, United States

Enrique Joffré,

Karolinska Institutet (KI), Sweden

*Correspondence:

Roy M. Robins-Browne r.browne@unimelb.edu.au

${ }^{\dagger}$ These authors share first authorship

Specialty section This article was submitted to Infectious Diseases, a section of the journal

Frontiers in Microbiology

Received: 09 January 2021

Accepted: 17 February 2021

Published: 18 March 2021

Citation

Carroll CJ, Hocking DM

Azzopardi Kl, Praszkier J,

Bennett-Wood V, Almeida K, Ingle DJ,

Baines SL, Tauschek $M$ and

Robins-Browne RM (2021)

Re-evaluation of a Neonatal Mouse

Model of Infection With

Enterotoxigenic Escherichia coli.

Front. Microbiol. 12:651488.

doi: 10.3389/fmicb.2021.651488
Carla J. Carroll1t, Dianna M. Hocking ${ }^{1 \dagger}$, Kristy I. Azzopardi1,2, Judyta Praszkier ${ }^{1}$, Vicki Bennett-Wood', Kaylani Almeida', Danielle J. Ingle' ${ }^{1}$, Sarah L. Baines ${ }^{1}$, Marija Tauschek ${ }^{1}$ and Roy M. Robins-Browne ${ }^{1,2 *}$

'Department of Microbiology and Immunology, The University of Melbourne at the Peter Doherty Institute for Infection and Immunity, Parkville, VIC, Australia, ${ }^{2}$ Murdoch Children's Research Institute, Royal Children's Hospital, Parkville, VIC, Australia

Enterotoxigenic E. coli (ETEC) is a common cause of diarrhea in children in low- and middle-income countries, and in travelers to these countries. ETEC is also an important cause of morbidity and premature mortality in piglets, calves, goat kids and lambs. The major virulence determinants of ETEC are enterotoxins and colonization factors, which enable the pathogen to colonize the small intestine and deliver enterotoxins, such as the heat-stable enterotoxins, STp and STh, to epithelial cells. Because most ETEC strains are host-specific, there are few convenient animal models to investigate the pathogenesis of ETEC infections or to evaluate specific anti-ETEC interventions, such as drugs and vaccines. An exception is ETEC strains bearing F41 pili, which mediate intestinal colonization of various young animals, including neonatal mice, to cause disease and in some cases death. In this study, we used the archetypal F41-producing bovine ETEC strain, B41 (O101:NM; K99, F41, STp) to validate and further explore the contribution of F41 and STp to bacterial virulence. By using targeted gene deletion and trans-complementation studies, augmented by whole genome sequencing, and in vitro and animal studies of virulence, we established that F41 mediates colonization of the mouse intestine and is essential for bacterial virulence. In addition, we showed for the first time that STp is as important as F41 for virulence. Together, these findings validate the use of neonatal mice to study the pathogenesis of F41-bearing ETEC and to investigate possible specific anti-ETEC interventions including vaccines that target heat-stable enterotoxins.

Keywords: enterotoxigenic E. coli, animal model, F41 pili, heat-stable enterotoxin, molecular Koch's postulates

\section{INTRODUCTION}

Enterotoxigenic Escherichia coli (ETEC) is a leading cause of diarrhea in children in low- to middleincome countries and in travelers of all ages to these countries (Qadri et al., 2005; Croxen et al., 2013; Kotloff et al., 2013). ETEC is also an important cause of diarrhea in young farm animals, in particular piglets, calves, lambs, and goat kids (Dubreuil et al., 2016).

ETEC are characterized by two categories of virulence determinant: secreted enterotoxins and surface-expressed colonization factors (Croxen et al., 2013). The enterotoxins are further divided 
into two broad groups, known as heat-stable toxin (ST) and heatlabile toxin (LT) (Croxen et al., 2013). The commonest variety of ST, STa, is highly prevalent in human varieties of ETEC, as well as in strains obtained from newborn domestic animals. It is a weakly antigenic protein comprising 18 (STp) or 19 (STh) amino acids, respectively (Fleckenstein et al., 2010). Although STh (also known as STIb) is more frequent in ETEC obtained from humans than STp (also known as STIa), these two toxins are structurally similar, have an identical mechanism of action and are antigenically related. LT, on the other hand, is a large (ca. $86 \mathrm{kDa}$ ) protein containing one A-subunit and five identical B-subunits. This toxin resembles cholera toxin structurally, functionally, and antigenically (Kunkel and Robertson, 1979).

The colonization factors, which are the other essential virulence determinant of ETEC, mediate bacterial adhesion to the small intestinal mucosa where the enterotoxins mainly act. These adhesins vary considerably in terms of their amino acid composition, structure, morphology and antigenic relatedness (Gaastra and Svennerholm, 1996; Croxen et al., 2013). Although the receptors for most of these colonization factors are not known, these receptors are generally host specific, meaning that there is negligible overlap between the host range of individual ETEC strains, particularly between those found in humans and those from domestic animals.

The number of different colonization factors of ETEC obtained from symptomatic humans exceeds 20, whereas those obtained from diarrheic piglets, calves, goat kids or lambs are limited to around six, including F4 (also known as K88), F5 (K99), F6 (987P), F17, F18, and F41. Interestingly, some of these colonization factors overlap in their host range. The least specific of these factors is F41, a fimbrial adhesin of bovine ETEC that is also able to mediate intestinal colonization of lambs, goat kids and piglets (Dubreuil et al., 2016; Luppi, 2017). The basis of F41's versatility is unknown but could be due to its ability to bind to different receptors (Lindahl and Wadström, 1986) or to the same receptor in different hosts.

In addition to infecting various natural hosts, ETEC strain B41, the archetypal bovine ETEC strain in which F41 was first identified, can also infect suckling mice to cause an infection that is often fatal (Duchet-Suchaux, 1980; Bertin, 1983). This makes E. coli B41 a convenient tool with which to investigate the pathogenesis of ETEC infections in a small animal model, as well as a means to evaluate early phase, anti-ETEC therapies and vaccines. Another unusual feature of E. coli B41, is that, apart from the chromosomally encoded F41 adhesin, it also carries a plasmid for K99. While K99 is likely to enhance the pathogenicity of B41 for calves, lambs and piglets, it does not play a major role in B41's virulence for neonatal mice (Bertin, 1985; Duchet-Suchaux, 1988).

Previous studies have provided strong circumstantial, but incomplete, evidence that F41 is an essential virulence determinant of E. coli B41, and none has investigated the role of its STp enterotoxin in the mouse model. The aim of the current study was to determine the contributions of F41 and STp to the virulence of E. coli B41 in a neonatal mouse model of ETEC infection.

\section{MATERIALS AND METHODS}

\section{Bacterial Strains, Plasmids, Primers, and Media}

Bacterial strains and plasmids used in this study are listed in Table 1. PCR primers were purchased from GeneWorks and are shown in Supplementary Table 1.

Except where indicated, bacteria were grown in Luria-Bertani broth (LB) or on Luria agar (LA) at $37^{\circ} \mathrm{C}$. When required, antibiotics were used at the following concentrations: ampicillin $100 \mu \mathrm{g} / \mathrm{ml}$, chloramphenicol $10 \mu \mathrm{g} / \mathrm{ml}$, kanamycin $40 \mu \mathrm{g} / \mathrm{ml}$, streptomycin $50 \mu \mathrm{g} / \mathrm{ml}$. Also used were Trypticase soy agar (TSA), SOB and SOC media (Hanahan, 1983). Minimal casein (Minca) media were prepared as described (Guinée et al., 1976) and used to grow bacteria when expression of F41 pili was desired (de Graaf and Roorda, 1982). To enhance production of enterotoxin, bacteria were grown in casamino and yeast extract (CAYE) medium (Evans et al., 1973). All chemical reagents were purchased from Ajax Chemicals, Sigma-Aldrich or BDH Laboratory Supplies unless otherwise specified.

\section{DNA Manipulation}

Restriction enzyme digestions were performed using enzymes and buffers from New England BioLabs (NEB) according to the manufacturer's instructions. DNA sequencing of PCR amplicons was performed using the BigDye terminator (v3.1) cycle sequencing kit (Applied Biosystems) in accordance with the manufacturer's instructions. Sequencing reactions were completed in a GeneAmp PCR system 9700 thermal cycler (Applied Biosystems), and the results were analyzed using Sequencher (Gene Codes). PCR amplifications were performed using GoTaq Green Master Mix (Promega), or Phusion Flash High-Fidelity PCR Master Mix (Finnzymes). To construct the plasmids used in this study, we first cloned the various PCR fragments into pCR2.1-TOPO (Invitrogen/Life Technologies) or pGEM-T Easy (Promega). Following sequence verification, we cloned the various inserts from the pCR2.1-TOPO or pGEM-T Easy derivatives into the appropriate vectors (Table 1).

\section{Construction of F41 and STp Knockout Mutants of E. coli B41 and Their Bioluminescent Derivatives}

The $\lambda$ Red recombinase system (Datsenko and Wanner, 2000) was used to construct a knockout mutation in $f 41 \mathrm{~A}$, the gene for the $29-\mathrm{kDa}$, major structural subunit of the F41 pilus of E. coli B41 (Fidock et al., 1989). First, the Phusion high-fidelity DNA polymerase, the primer pairs, F41.F1/F41.R1, and plasmid, pKD4, were used in a PCR reaction to generate a DNA fragment that contained the kanamycin-resistance gene ( $a p h\left(3^{\prime}\right)$-IIa) flanked by ca. 50-bp DNA sequences corresponding to the upstream and downstream regions of the $f 41 A$ gene. This linear DNA fragment was then transformed by electroporation into E. coli B41, which carried plasmid pKD46, encoding the $\lambda$ Red recombinase system. The resultant $f 41 A$ :aph $\left(3^{\prime}\right)$-IIa mutant, B41 $\Delta \mathrm{F} 41$, was confirmed by PCR using primer pairs pKD4Fs/B41R and pKD4Rs/B41F. The same method was used to construct a estA:aph(3')-IIa 
TABLE 1 | Bacterial strains and plasmids used in this study.

\begin{tabular}{|c|c|c|}
\hline Strain or plasmid & Relevant characteristics & References/source \\
\hline \multicolumn{3}{|l|}{ E. coli strains } \\
\hline B41 & Streptomycin-resistant derivative of bovine ETEC strain O101:NM; F41, K99, STa, Sm ${ }^{R}$ & Smith and Halls, 1967 \\
\hline $\mathrm{B} 41 \Delta \mathrm{F} 41$ & B41 f41A:aph(3')-Ila, $\mathrm{Km}^{R}$ & This study \\
\hline $\mathrm{B} 41 \Delta \mathrm{F} 41(\mathrm{~F} 41)$ & $\mathrm{B} 41 \Delta \mathrm{F} 41(\mathrm{pACYC} 184: f 41 \mathrm{~A}), \mathrm{Km}^{R}, \mathrm{Cm}^{R}$ & This study \\
\hline $\mathrm{B} 41 \Delta \mathrm{STp}$ & B41 estA:aph(3')-Ila, $\mathrm{Km}^{R}$ & This study \\
\hline HS & Non-pathogenic $E$. coli of human origin & Levine et al., 1978 \\
\hline MC4100 & $\mathrm{F}^{-}$araD139 (argF-lac) lacU169 rpsL150 relA1 flbB5301 deoC1 ptsF25 rbsR thiA & Casadaban, 1976 \\
\hline TOP10 & $\begin{array}{l}\mathrm{F}^{-} \text {mcrA } \Delta\left(\mathrm{mrr}^{-}, \text {hsdRMS }\right. \\
\Delta(\text { ara-leu }) 7697 \text { galE15 galK16 } \operatorname{rps} L\left(\mathrm{Str}^{R}\right) \text { end } A 1 \lambda^{-}\end{array}$ & Invitrogen \\
\hline \multicolumn{3}{|l|}{ Plasmids } \\
\hline pACYC184 & Medium-copy number vector, $\mathrm{Cm}^{R}, \mathrm{Tc}^{R}$ & Chang and Cohen, 1978 \\
\hline \multirow[t]{2}{*}{ pACYC184:f41A } & pACYC184 containing $f 41 A$, the gene for the & This study \\
\hline & $29 \mathrm{kDa}$ major subunit of the F41 pilus, $\mathrm{Cm}^{R}$ & \\
\hline pCR2.1-TOPO & High-copy number vector, $\mathrm{Ap}^{R}, \mathrm{Km}^{R}$ & Invitrogen \\
\hline pGEM-T Easy & High-copy number vector, $\mathrm{Ap}^{R}$ & Promega \\
\hline pKD4 & Vector containing $\mathrm{Km}^{R}$ gene, $\mathrm{Ap}^{R}, \mathrm{Km}^{R}$, & Datsenko and Wanner, 2000 \\
\hline pKD46 & Low-copy number vector, $P_{B A D}-\lambda$ red, $A p^{R}$ & Datsenko and Wanner, 2000 \\
\hline pXen-13 & $\mathrm{pSK} / \mathrm{uxCDABE}, \mathrm{Ap}^{R}$ & Xenogen \\
\hline
\end{tabular}

$A p^{R}$, ampicillin resistance; $\mathrm{Cm}^{R}$, chloramphenicol resistance; $\mathrm{Km}^{R}$, kanamycin resistance; $\mathrm{Sm}^{R}$, streptomycin resistance; $T^{R}$, tetracycline resistance.

mutant, B41 $\Delta$ STp, except that primers STpF1 and STpR1 were used to generate $a p h\left(3^{\prime}\right)$-IIa flanked by DNA sequences of the upstream and downstream regions of the estA gene (also known as sta1). Primer pairs STpFseq/pKD4Rs, and pKD4Fs/STpRseq were used to confirm the estA:aph(3')-IIa mutation in B41.

Bioluminescent derivatives of E. coli B41 and its isogenic F41 and STp knockout mutants were obtained by transforming each strain with the luciferase-encoding plasmid, pXen-13 (Xenogen). The F41 and STp knockout mutant strains (B41 $\Delta$ F41 and B41 $\Delta$ STp, respectively), their bioluminescent derivatives, and the F41-transcomplemented strain, B41 $\Delta$ F41 (F41), all grew at the same rate in vitro as the $E$. coli B41 wild-type.

\section{Whole Genome Sequencing and Genomic Analyses}

Three isolates of E. coli B41: wild-type, B41 $\Delta$ F41 and B41 $\Delta$ STp, were sequenced on the NextSeq 500 platform (Illumina) using methods described previously (Ingle et al., 2019). All three isolates passed quality control with phred scores of 33 and average read depth $>100$. Sequence data for the three isolates were mapped to the publicly available near complete E. coli B41 genome (accession AFAH02000000) using snippy v4.3.3 ${ }^{1}$. De novo assembly was conducted with SPAdes (v3.13.0) (Bankevich et al., 2012). The short read data are available at the European Nucleotide Archive under BioProject PRJEB34804 ${ }^{2}$ as: ERR3587299 (B41 wild-type), ERR3587300 (B41 $\Delta$ STp), and ERR5014780 (B41 $\Delta$ F41).

Genomes were screened for known antimicrobial resistance genes with the NCBI database, plasmid replicons with PlasmidFinder database (Carattoli et al., 2014), and for enterotoxin and fimbriae-encoding genes available in the

\footnotetext{
${ }^{1}$ https://github.com/tseemann/snippy

${ }^{2}$ https://www.ebi.ac.uk/ena/browser/view/PRJEB34804
}

AMRFinderPlus database ${ }^{3}$, performed using ABRicate ${ }^{4}$ with minimum coverage and minimum identity thresholds of $95 \%$.

\section{Suckling Mouse Assay for ST}

E. coli strains B41, its isogenic STp and F41 mutants (B41 $\Delta$ STp, $\mathrm{B} 41 \Delta \mathrm{F} 41$ ), and HS (negative control) were each inoculated into $10 \mathrm{ml} \mathrm{CAYE}$ broth and incubated with shaking for $18 \mathrm{~h}$ at $37^{\circ} \mathrm{C}$. Bacteria were pelleted by centrifugation at $4,000 \times g$ at $4^{\circ} \mathrm{C}$ for $20 \mathrm{~min}$, after which $2 \mathrm{ml}$ of each supernatant was removed, and stored on ice until required. STa activity was measured in a suckling mouse assay as described previously with minor modifications (Robins-Browne and Levine, 1981). Briefly, 4-6 days old $\mathrm{BALB} / \mathrm{c}$ mice were separated from their mothers $2 \mathrm{~h}$ before use and then randomly divided into groups of four. Each mouse was inoculated by oral gavage using a $22 \mathrm{G} 1.5$ inch blunt feeding needle (Cole-Parmer Instruments), with $100 \mu \mathrm{l}$ of culture supernatant or PBS containing $10 \mu \mathrm{l}$ of $1 \%$ Evans blue dye per $\mathrm{ml}$. Ninety minutes after inoculation, mice were weighed, killed by decapitation, the abdomen was opened and the entire intestinal tract from the proximal duodenum to the distal rectum was removed. The intestines were weighed and the gut to body weight ratio was calculated.

\section{Assays for F41 Pili}

The presence of intact F41 pili on E. coli B41 and its isogenic derivates was inferred by the demonstration of the $29 \mathrm{kDa}$ major subunit of F41 using SDS-PAGE, and by the ability of strains to hemagglutinate human blood group A erythrocytes and adhere to HeLa epithelial cell monolayers.

To extract bacterial surface proteins for analysis by SDSPAGE, E. coli B41 and its derivatives were grown overnight in

\footnotetext{
${ }^{3}$ https://www.ncbi.nlm.nih.gov/pathogens/antimicrobial-resistance/AMRFinder/

${ }^{4}$ https://github.com/tseemann/abricate
} 
Minca broth without shaking and on Minca agar at $37^{\circ} \mathrm{C}$. Cells were harvested by centrifugation of Minca broth and gentle scraping of Minca agar, washed in PBS ( $\mathrm{pH} 7.4$ ), vortexed for $1 \mathrm{~min}$, and incubated at $60^{\circ} \mathrm{C}$ for $20 \mathrm{~min}$ with intermittent vortexing. Samples were then pelleted by centrifugation at $3,000 \times g$ for $10 \mathrm{~min}$, and the supernatant was transferred to a fresh tube, where it was mixed with NuPAGE lithium dodecyl sulfate sample reducing buffer (Thermo Fisher Scientific) and heated at $70^{\circ} \mathrm{C}$ for $10 \mathrm{~min}$. Samples $(25 \mu \mathrm{l})$ were then separated by SDS-PAGE using 12\% Bis-Tris NuPAGE gels (Invitrogen), alongside protein ladder standards (BioRAD), and the separated proteins were stained with Coomassie brilliant blue G250. A $\sim 29 \mathrm{kDa}$ band of interest was excised, trypsin-digested, and analyzed by tandem mass spectrometry at the Proteomics Laboratory, Walter and Eliza Hall Institute of Medical Research, Melbourne, Australia.

For the hemagglutination assays, bacteria were grown overnight in standing cultures of Minca broth and resuspended to a concentration of $\sim 10^{11} \mathrm{cfu} / \mathrm{ml}$. Doubling dilutions were made and mixed 1:1 with $3 \%(\mathrm{v} / \mathrm{v})$ human blood group A erythrocytes in $0.9 \%(\mathrm{w} / \mathrm{v})$ saline with $1 \%(\mathrm{w} / \mathrm{v})$ methyl- $\alpha$-D-mannoside (Sigma-Aldrich) on ceramic plates. Agglutination readings were made after gentle rocking at room temperature for $10 \mathrm{~min}$.

Assays for bacterial adherence to cultured HeLa cells were performed as described by Vial et al. (1990) with some modifications. Briefly, bacteria were grown overnight in Minca broth without shaking, and after washing with PBS, approximately $2 \times 10^{7} \mathrm{cfu}$ were added to semi-confluent monolayers of HeLa cells on cover slips in 24-well tissue culture plates containing minimal essential media (MEM; ICN) with $8 \%$ (w/v) fetal calf serum, $20 \mathrm{mM}$ HEPES (Sigma-Aldrich) and 1\% $(\mathrm{w} / \mathrm{v})$ methyl- $\alpha$-D-mannoside. Plates were incubated for $3 \mathrm{~h}$ at $37^{\circ} \mathrm{C}$ in $5 \% \mathrm{CO}_{2}$, and then washed three times in PBS, fixed in methanol and stained in $10 \%(\mathrm{w} / \mathrm{v})$ Giemsa stain for $7 \mathrm{~min}$. Coverslips were then washed briefly in Giemsa buffer and allowed to dry before being applied to glass microscope slides with a drop of DePex mounting medium (BHD Merck). After being left to dry overnight, cells were visualized with a Leica DM LB optical microscope. Bacterial strains were designated non-adherent if fewer than 10 of 200 HeLa cells had 5 or more attached bacteria.

\section{Infection of Neonatal Mice}

The virulence of $E$. coli $\mathrm{B} 41$ or its derivatives was investigated in genetically verified $\mathrm{CBA}, \mathrm{BALB} / \mathrm{c}$ and $\mathrm{C} 57 \mathrm{BL} / 6$ neonatal mice. Bacterial strains used to infect mice were cultured on LA overnight at $37^{\circ} \mathrm{C}$. On the day of infection, fresh cultures were collected with a wet sterile cotton swab and suspended in $10 \mathrm{ml}$ of PBS, the turbidity of which was compared to McFarland standards to achieve a dose of $\sim 2 \times 10^{6} \mathrm{cfu}$ in $10 \mu \mathrm{l}$. The number of bacteria in the $10 \mu \mathrm{l}$ inoculum was determined retrospectively by using the surface viable count method of Miles et al. (1938).

Mice were infected perorally by gently pushing the tip of a 10 $\mu l$ pipette into the side of their mouth, delivering the inoculum in 2-3 $\mu$ l doses over $\sim 2 \mathrm{~min}$. Mice were returned to their mothers and monitored for signs of disease, including failure to gain weight, non-responsiveness, dull color, inactivity, shaking, labored breathing, dehydration (skin tenting lasting more than
5 s) and the presence of diarrhea, up to three times daily for 9 days. Disease was classified as "lethal" when mice displayed two or more of these and had to be culled in accordance with our ethics committee's protocol.

To visualize the location of bacteria in mice, neonatal $\mathrm{BALB} / \mathrm{c}$ mice in groups of three were infected as described above with $E$. coli B41 or its derivatives transformed with the luciferase-encoding plasmid, pXen-13. After $40 \mathrm{~h}$, mice were killed by decapitation, and the entire intestine from proximal duodenum to distal rectum was excised, teased out on filter paper and visualized semi-quantitatively using an enhanced chemiluminescence system and digital imaging (DNR ChemiBis).

All experiments involving animals were approved by a University of Melbourne Animal Experimentation and Ethics Committee and were performed in accordance with the guidelines for animal experimentation of the Australian National Health and Medical Research Council.

\section{Statistical Analysis}

GraphPad Prism version 8.4.3 was used for plotting graphs and statistical analysis. Quantitative data were analyzed by using oneway ANOVA; qualitative data by using Chi-squared or Fisher's exact test. Survival curves were derived using Kaplan-Meier estimates, and the log rank test was used to compare different groups. For all tests, a $P$-value of $<0.05$ was taken to indicate statistical significance.

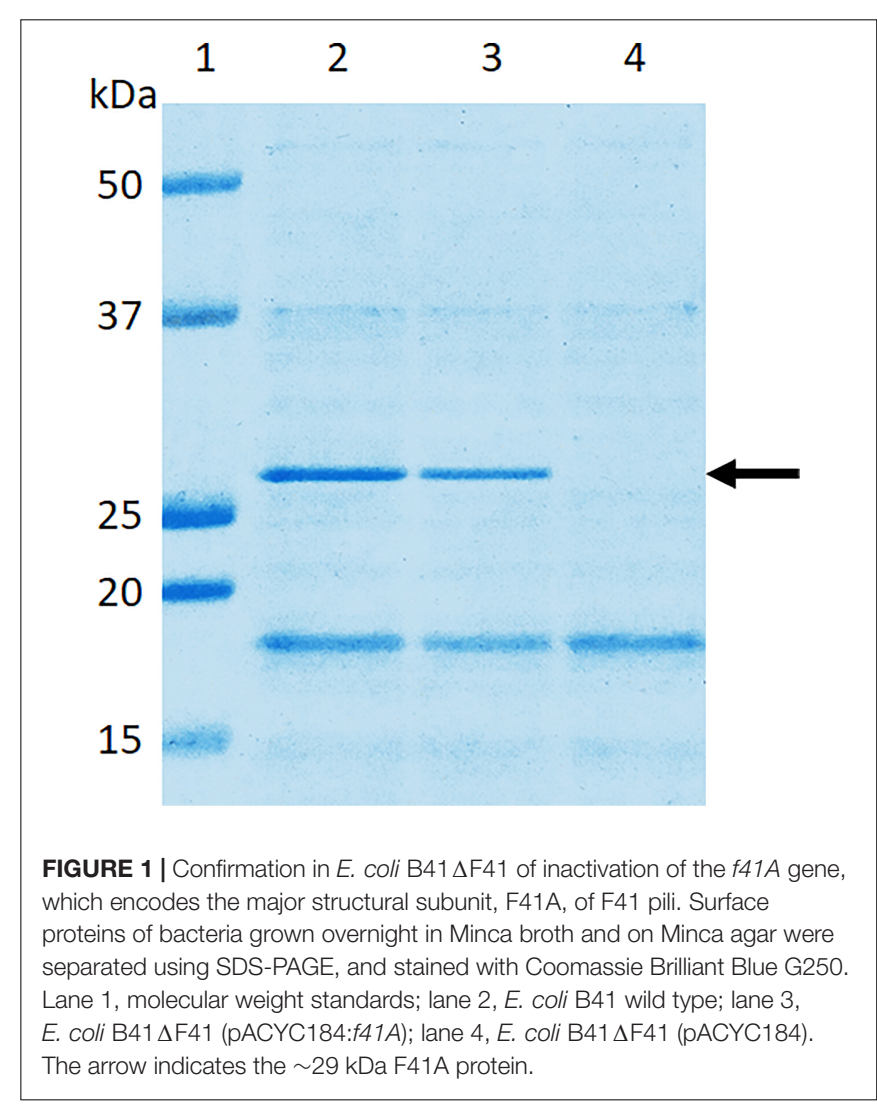




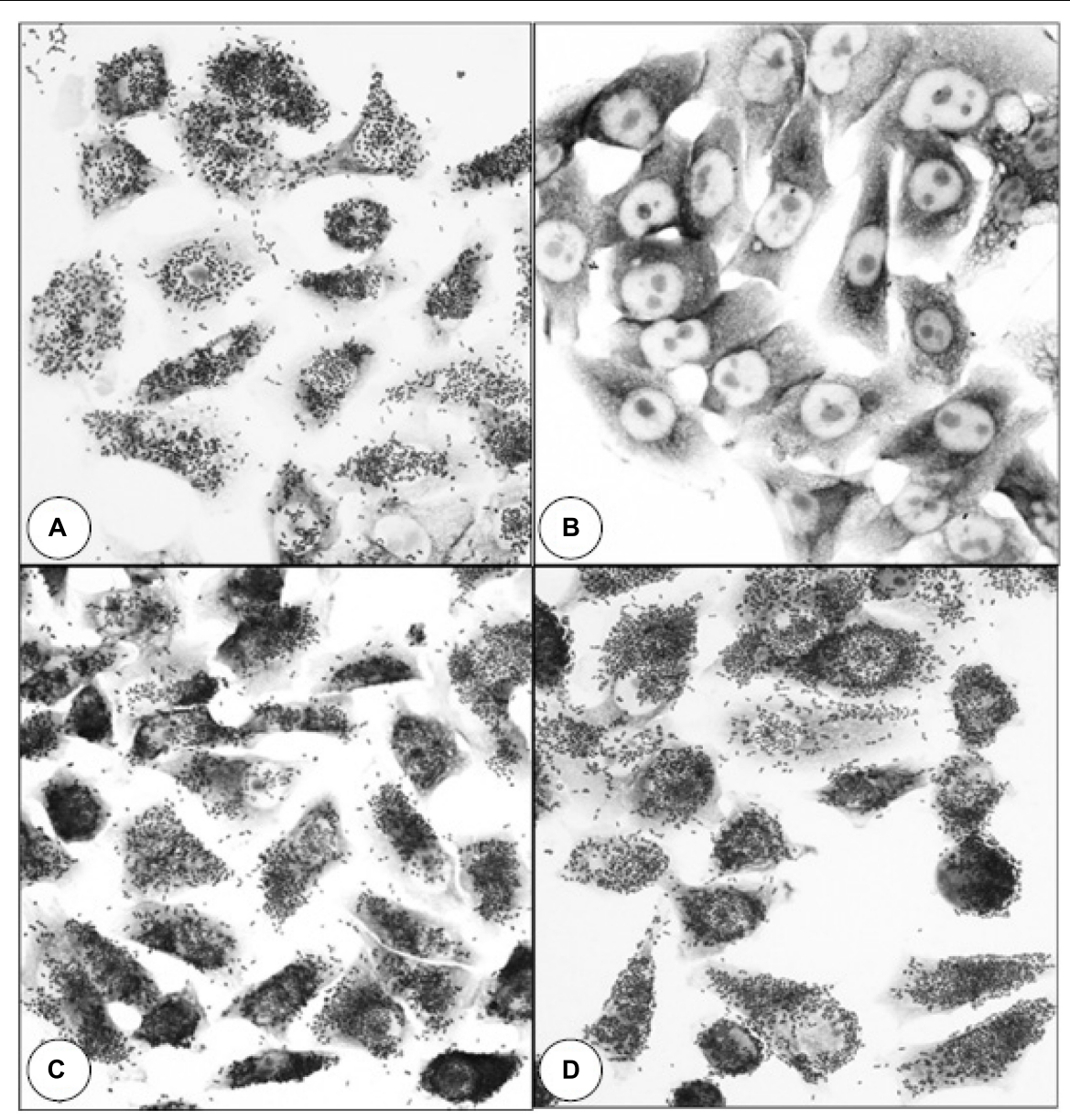

FIGURE 2 | Effect of inactivating f41A in E. coli B41 on bacterial adherence to HeLa cells. (A) E. coli B41 wild-type. (B) E. coli B41 $\triangle$ F41 (pACYC184). (C) E. coli $\mathrm{B} 41 \Delta \mathrm{F} 41$ (pACYC184:f41A). (D) E. coli B41 $\triangle \mathrm{STp}$. Similar results were obtained in assays for mannose-resistant agglutination of human blood group A erythrocytes (Supplementary Figure 2).

\section{RESULTS}

\section{Susceptibility of CBA, BALB/c, and C57BL/6 Mice to Infection With E. coli B41}

Duchet-Suchaux et al. (1990) have reported that infant CBA mice are somewhat more susceptible to infection with ETEC strain $\mathrm{B} 41$ than $\mathrm{BALB} / \mathrm{c}$ or $\mathrm{C} 57 \mathrm{BL} / 6$ mice. To verify these findings, we infected 1-day old CBA, BALB/c and C57BL/6 mice with $7 \times 10^{6}$ cfu of $E$. coli strain B41. Lethal infections occurred in 4 of 6 (67\%) CBA, 15 of 19 (79\%) BALB/c and 19 of 20 (95\%) C57BL/6 mice (Supplementary Figure 1). Almost 90\% of deaths (34 of 38 ) occurred within 4 days of infection, and no deaths occurred more than 5 days after infection. The difference in mortality of the different mouse strains was not statistically significant $(P>0.1$, Chi-squared test). All four CBA mice that succumbed to infection, died on day 1 (Supplementary Figure 1), but the difference between the survival curves for the three mouse strains was not significant ( $P=0.08, \log$ rank test). The flatter survival curve of BALB/c mice (Supplementary Figure 1), suggested that these mice may be best suited to detect subtle differences in virulence between bacterial strains. Accordingly, BALB/c mice were used for all future experiments.

\section{Genetic Analysis of E. coli B41 and Its F41 and STp Knockout Mutants}

We undertook whole-genome sequencing of E. coli B41 (wild-type) and its F41 and STp knockout mutants to ensure that no significant genetic changes had occurred while constructing the mutants.

All three isolates had $>97 \%$ coverage of the reference genome. Only one unintended sequence variant was detected between $\mathrm{B} 41 \Delta \mathrm{F} 41$, and both B41 wild-type and B41 $\Delta$ STp. This was a single nucleotide polymorphism $(\mathrm{C}>\mathrm{A})$ located in an intergenic region (position 482849 in contig AFAH02000003.1 of reference E. coli B41), amongst genes associated with flagellar function. The SNP had no obvious phenotype in terms of growth or motility, or on virulence after trans-complementation with $f 41 A$ (see below). No SNPs were detected between B41 wild-type and B41 $\Delta$ STp. As expected, both deletion mutants carried the $a p h\left(3^{\prime}\right)$-IIa gene 
for kanamycin resistance. All three strains had the same plasmid replicon profiles, indicating no loss of plasmids during in vitro manipulation. The $f 41 A$ gene (Fidock et al., 1989) was detected in both E. coli B41 wild-type and its B41 $\Delta$ STp derivative but was absent from B41 $\Delta$ F41. Similarly, the estA gene was detected in B41 wild-type and B4 $\Delta$ F41 but was absent from B41 $\Delta$ STp.

\section{In vitro Characterization of the F41 and ST Deletion Mutants of E. coli B41}

SDS-PAGE analysis of wild-type E. coli B41 showed a distinct band of around $29 \mathrm{kDa}$ that was absent from B41 $\Delta$ F41 (Figure 1). This band, which was shown by tandem mass spectrometry to be the major structural protein of F41, was restored to $\mathrm{B} 41 \Delta \mathrm{F} 41$ by trans-complementation of B $41 \Delta \mathrm{F} 41$ with pACYC184: $f 41 \mathrm{~A}$. These findings agreed with the results of functional assays for hemagglutination of human erythrocytes, and adhesion to HeLa cells, in which the wild-type and trans-complemented strains were positive, whereas the F41 mutant was negative (Figure 2).

In the suckling mouse assay for STa, both E. coli B41 and B41 $\triangle$ F41 were positive, with mean gut to body weight ratios of $0.093 \pm 0.01$ (mean $\pm S D$ ) and $0.095 \pm 0.01$, respectively. In contrast, the values for B41 $\Delta \mathrm{STp}$ and E. coli HS, the negative control, were $0.056 \pm 0.002$ and $0.058 \pm 0.002$, respectively. The differences between the two positive strains and B41 $\Delta$ STp were significant $(P<0.001$, one-way ANOVA), whereas the difference between B41 $\Delta$ STp and HS was not $(P>0.05)$.

\section{Investigation of F41 Pili and STp as Virulence Determinants of $E$. coli B41 in Mice}

None of the nine 1 day-old mice infected with the F41 mutant of E. coli B41 succumbed to infection, compared with 17 of 26 (65\%) of mice infected with the wild-type strain $(P=0.001$, Fisher's exact test). Kaplan-Meier analysis of these data showed that the probability of survival curves of mice infected with the two strains were significantly different from each other (Figure 3; $P<0.0001$, log rank test).

Bioluminescent tracking of E. coli B41 (pXen-13) wild-type, and its F41 and STp mutant derivatives $40 \mathrm{~h}$ after infection revealed no difference between the wild-type and B41 $\Delta$ STp, both of which had colonized various regions of the entire intestine from duodenum to distal rectum, whereas B41 $\Delta \mathrm{F} 41$ was restricted to the distal rectum in all three mice that received this strain (Figure 4). Despite the ability of E. coli B41 $\Delta$ STp to colonize mouse intestine, none of 14 mice infected with this strain died, compared with 17 of 26 that received the wild type (Figure 3; $P<0.0001$, Fisher's exact test).

\section{DISCUSSION}

In a landmark study, Smith and Linggood (1971) showed that both an adhesin (F4/K88) and enterotoxin are required for virulence of ETEC in piglets. Their study was facilitated by the facts that (1) both of the virulence factors they investigated were plasmid encoded, thus making F4- and enterotoxin-negative

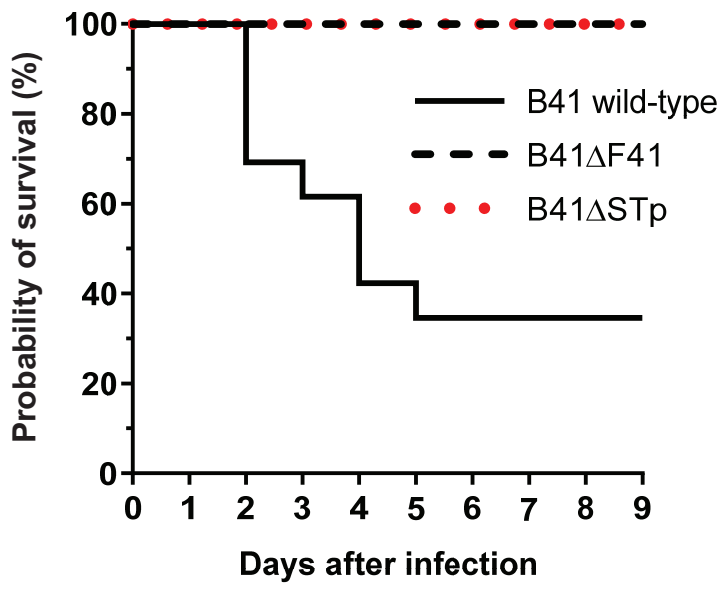

FIGURE 3 | Kaplan-Meier survival analysis of neonatal mice infected perorally with $\sim 2 \times 10^{6}$ cfu of E. coli B41 $(n=26)$ or B41 $\Delta$ F41 $(n=9)$ or B41 $\Delta$ STp $(n=14)$. After inoculation, mice were returned to their mothers and monitored for signs of disease up to three times daily for 9 days. Disease was classified as "lethal" when mice had to be culled due to illness. The probability of survival curves of mice that received either mutant strain differed significantly from those that received the wild-type strain $(P<0.0001$; log rank test).

strains relatively easy to obtain, and (2) piglets are the natural host of F4-positive, enterotoxin-secreting ETEC (Smith and Linggood, 1971). Subsequently, Bertin (1983) used a spontaneous mutant of E. coli B41, which did not produce F41, to show that F41 is a virulence determinant of this strain. Given that F41 is chromosomally encoded, a spontaneous mutant may have carried additional mutations that contributed to its loss of virulence. To address issues of this type, Falkow (1988) devised a set of criteria, called Molecular Koch's postulates, that should be fulfilled before one can be confident that a putative virulence determinant is indeed required by bacteria to cause disease. In essence, these criteria are first, that a strain in which the gene for a putative virulence determinant has been inactivated or deleted is significantly less virulent than the wild-type, and second, that reintroduction of the gene into the attenuated mutant restores virulence. These criteria have not been satisfied for either F41 or STp in ETEC strain B41. Nevertheless, there is considerable circumstantial evidence of the importance of F41 in virulence, including the protective efficacy of vaccines based on F41 (for example Duchet-Suchaux, 1988; Liu et al., 2014), and the passive administration of monoclonal antibodies directed against F41 to mouse dams to protect their suckling neonates from illness caused by E. coli B41 (Duchet-Suchaux et al., 1992; van Zijderveld et al., 1998). However, no similar studies have been reported for $\mathrm{ST}$, whose role in the infant mouse model of infection prior to our study was unknown.

In this study, we have shown that both F41 fimbriae and STp are required for virulence of $E$. coli B41 in neonatal mice. Regarding F41, we demonstrated that a genetically well-defined F41 mutant was non-adherent in vitro and completely avirulent in mice, and that trans-complementation of this mutant with 

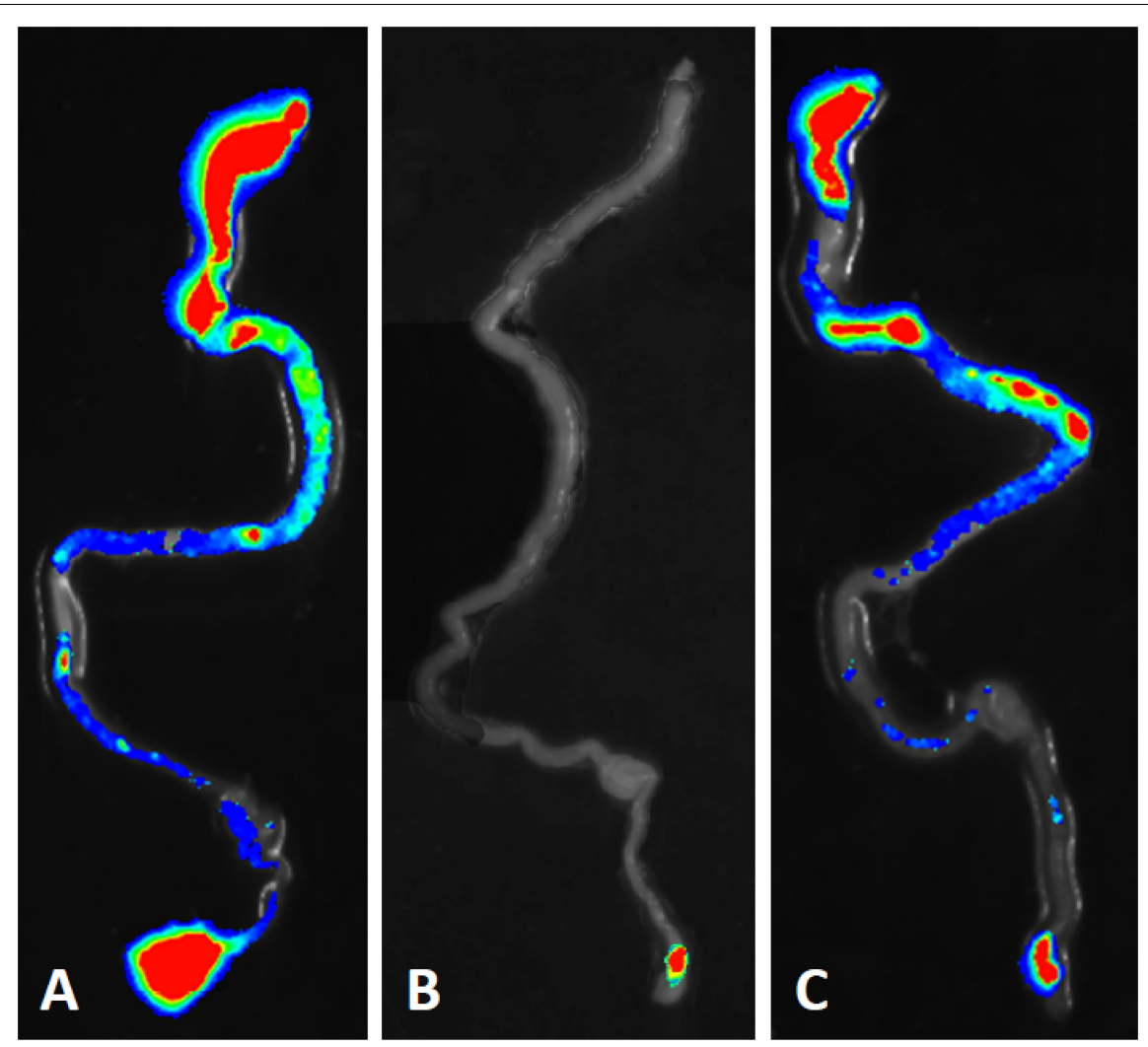

FIGURE 4 | Bioluminescent tracking of E. coli B41 (pXen-13) (A), and its F41 (B) and STp (C) knockout mutants in the intestines of neonatal mice. Neonatal BALB/c mice were infected perorally with derivatives of $E$. coli B41 (pXen-13). After $40 \mathrm{~h}$, mice were killed, their entire intestine was excised and visualized semi-quantitatively using enhanced chemiluminescence and digital imaging. The highest bacterial concentrations are represented by red, and then reduce in number through yellow, green, blue, and finally, no color.

$f 41 A$, the F41-encoding gene, restored both hemagglutination and adherence to HeLa cells. Because the trans-complementing plasmid we constructed was unstable in the absence of antibiotic selection, we were unable to investigate the trans-complemented strain in mice, however, whole genome sequencing showed that E. coli B41 and B41 $\mathrm{F} 41$ were identical in every respect except for the $f 41 A$ gene we interrupted to produce the F41 mutant, and one inadvertent nucleotide substitution, which our trans-complementation data indicated was likely to be irrelevant. In addition, by using bioluminescence tracing we established that the F41 mutant colonized the mouse intestine far less effectively than two different F41-bearing strains, namely, E. coli B41 wild-type and its isogenic STp deletion mutant, B41 $\Delta$ STp.

Regarding STp, we showed for the first time that this toxin is as important as F41 for the virulence of E. coli B41 in the mouse model. Because our laboratory is not authorized to clone toxin genes into multicopy plasmids in their natural host, in this case, E. coli, we did not attempt to trans-complement B41 $\Delta \mathrm{STp}$, but instead performed whole genome sequencing which showed that E. coli B41 and B41 $\Delta$ STp were identical in every respect except for the gene we interrupted to produce the STp mutant. The ability to analyze whole genome sequences can supplement Molecular Koch's postulates, because if the data reveal that the mutant is identical to the wild-type in all respects other than the gene being investigated, the need for trans-complementation studies is obviated.

For any animal model of infection to be valid, it should mimic infection in the normal host as closely as possible. With regard to the suckling mouse model of infection with E. coli B41, the bacterium's two essential virulence determinants, F41 and STa, appear to bind to the same receptors and act in mice in the same manner as in E. coli B41's natural hosts. Specifically, STa uses the same receptor, namely, guanylyl cyclase C (GC-C) in mice as in humans and other animals (Swenson et al., 1996; Schulz et al., 1997). Our observation that E. coli B41 $\Delta \mathrm{STp}$ colonized mouse intestine extensively without causing any disease mirrors findings in piglets infected with a spontaneous ST-mutant of an F41-positive ETEC strain (Casey and Moon, 1990). Regarding F41 itself, van Zijderveld et al. (1998) have shown that the same monoclonal antibodies directed against various epitopes of F41 protect both mice and this piglets from infection with F41positive ETEC. This could be interpreted as indicating that F41 binds to the same or similar receptor(s) in piglets and mice, or that antibodies to different regions of F41 can block its binding regardless of the receptor.

Nevertheless, taken together with the clinical and pathological observations associated with B41 infection of neonatal mice 
published previously (Duchet-Suchaux, 1980; Bertin, 1983; Newsome et al., 1987), our demonstration that both F41 and STp are required for full virulence of $E$. coli B41 in neonatal mice, validates this model completely. Our findings also indicate that the model may be useful for screening vaccine candidates for ST-producing ETEC by using active immunization of dams followed by experimental challenge of suckling pups as described elsewhere (Duchet-Suchaux, 1983; Liu et al., 2014).

\section{DATA AVAILABILITY STATEMENT}

The datasets presented in this study can be found in online repositories. The names of the repository/repositories and accession number(s) can be found below: https://www.ebi.ac.uk/ ena, ERR3587299; ERR3587300; ERR5014780.

\section{ETHICS STATEMENT}

The animal study was reviewed and approved by the University of Melbourne Small Laboratory Animal Ethics Committee.

\section{REFERENCES}

Bankevich, A., Nurk, S., Antipov, D., Gurevich, A. A., Dvorkin, M., Kulikov, A. S., et al. (2012). SPAdes: a new genome assembly algorithm and its applications to single-cell sequencing. J. Comput. Biol. 19, 455-477. doi: 10.1089/cmb.2012. 0021

Bertin, A. (1983). Virulence factors of enterotoxigenic E. coli studied in the infant mouse model. Ann. Rech. Vet. 14, 169-182.

Bertin, A. (1985). F41 antigen as a virulence factor in the infant mouse model of Escherichia coli diarrhoea. J. Gen. Microbiol. 131, 3037-3045. doi: 10.1099/ 00221287-131-11-3037

Carattoli, A., Zankari, E., García-Fernández, A., Larsen, M. V., Lund, O., Villa, L., et al. (2014). In silico detection and typing of plasmids using PlasmidFinder and plasmid multilocus sequence typing. Antimicrob. Agents Chemother. 58, 3895-3903. doi: 10.1128/AAC.02412-14

Casadaban, M. J. (1976). Transposition and fusion of the lac genes to selected promoters in Escherichia coli using bacteriophage lambda and Mu. J. Mol. Biol. 104, 541-555. doi: 10.1016/0022-2836(76)90119-4

Casey, T. A., and Moon, H. W. (1990). Genetic characterization and virulence of enterotoxigenic Escherichia coli mutants which have lost virulence genes in vivo. Infect. Immun. 58, 4156-4158. doi: 10.1128/IAI.58.12.4156-4158.1990

Chang, A. C., and Cohen, S. N. (1978). Construction and characterization of amplifiable multicopy DNA cloning vehicles derived from the P15A cryptic miniplasmid. J. Bacteriol. 134, 1141-1156. doi: 10.1128/JB.134.3.1141-1156. 1978

Croxen, M. A., Law, R. J., Scholz, R., Keeney, K. M., Wlodarska, M., and Finlay, B. B. (2013). Recent advances in understanding enteric pathogenic Escherichia coli. Clin. Microbiol. Rev. 26, 822-880. doi: 10.1128/CMR.00022-13

Datsenko, K. A., and Wanner, B. L. (2000). One-step inactivation of chromosomal genes in Escherichia coli K-12 using PCR products. Proc. Natl. Acad. Sci. U.S.A 97, 6640-6645. doi: 10.1073/pnas.120163297

de Graaf, F. K., and Roorda, I. (1982). Production, purification, and characterization of the fimbrial adhesive antigen F41 isolated from calf enteropathogenic Escherichia coli strain B41M. Infect. Immun. 36, 751-758. doi: 10.1128/IAI.36.2.751-758.1982

Dubreuil, J. D., Isaacson, R. E., and Schifferli, D. M. (2016). Animal Enterotoxigenic Escherichia coli. EcoSal Plus doi: 10.1128/ecosalplus.ESP-00062016

Duchet-Suchaux, M. (1980). Infant mouse model of Escherichia coli infectious diarrhoea (author's transl). Ann. Microbiol. (Paris). 131B, 239-250.

\section{AUTHOR CONTRIBUTIONS}

CC, DH, JP, MT, and RR-B designed and performed most of the experiments and contributed to the analysis and interpretation of data. DH, KIA, JP, VB-W, and KA carried out some experiments. $\mathrm{DI}$ and $\mathrm{SB}$ analyzed the genome sequences. CC, DH, KA, and RR-B prepared the figures for publication. CC and RR-B wrote the manuscript. All authors reviewed the manuscript before submission.

\section{FUNDING}

This work was supported by grants from the Australian National Health and Medical Research Council (NHMRC) and the University of Melbourne.

\section{SUPPLEMENTARY MATERIAL}

The Supplementary Material for this article can be found online at: https://www.frontiersin.org/articles/10.3389/fmicb. 2021.651488/full\#supplementary-material

Duchet-Suchaux, M. (1983). Infant mouse model of E. coli diarrhoea: clinical protection induced by vaccination of the mothers. Ann. Rech. Vet. 14, 319-331.

Duchet-Suchaux, M. (1988). Protective antigens against enterotoxigenic Escherichia coli O101:K99,F41 in the infant mouse diarrhea model. Infect. Immun. 56, 1364-1370. doi: 10.1128/IAI.56.5.1364-1370.1988

Duchet-Suchaux, M., Le Maitre, C., and Bertin, A. (1990). Differences in susceptibility of inbred and outbred infant mice to enterotoxigenic Escherichia coli of bovine, porcine and human origin. J. Med. Microbiol. 31, 185-190. doi: 10.1099/00222615-31-3-185

Duchet-Suchaux, M., Menanteau, P., and van Zijderveld, F. G. (1992). Passive protection of suckling infant mice against F41-positive enterotoxigenic Escherichia coli strains by intravenous inoculation of the dams with monoclonal antibodies against F41. Infect. Immun. 60, 2828-2834. doi: 10.1128/IAI.60.7. 2828-2834.1992

Evans, D. J., Evans, D. G., and Gorbach, S. L. (1973). Production of a vascular permeability factor by enterotoxigenic Escherichia coli isolated from man. Infect. Immun. 8, 725-730. doi: 10.1128/IAI.8.5.725-730.1973

Falkow, S. (1988). Molecular Koch's postulates applied to microbial pathogenicity. Rev. Infect. Dis. 10(Suppl 2), S274-S276. doi: 10.1093/cid/10.supplement_2. s274

Fidock, D. A., McNicholas, P. A., and Lehrbach, P. R. (1989). Nucleotide sequence of the F41 fimbriae subunit gene in Escherichia coli B41. Nucleic Acids Res. 17:2849. doi: 10.1093/nar/17.7.2849

Fleckenstein, J. M., Hardwidge, P. R., Munson, G. P., Rasko, D. A., Sommerfelt, H., and Steinsland, H. (2010). Molecular mechanisms of enterotoxigenic Escherichia coli infection. Microbes. Infect. 12, 89-98. doi: 10.1016/j.micinf.2009. 10.002

Gaastra, W., and Svennerholm, A. M. (1996). Colonization factors of human enterotoxigenic Escherichia coli (ETEC). Trends Microbiol. 4, 444-452. doi: 10.1016/0966-842x(96)10068-8

Guinée, P. A., Jansen, W. H., and Agterberg, C. M. (1976). Detection of the K99 antigen by means of agglutination and immunoelectrophoresis in Escherichia coli isolates from calves and its correlation with entertoxigenicity. Infect. Immun. 13, 1369-1377. doi: 10.1128/IAI.13.5.1369-1377.1976

Hanahan, D. (1983). Studies on transformation of Escherichia coli with plasmids. J. Mol. Biol. 166, 557-580. doi: 10.1016/s0022-2836(83)80284-8

Ingle, D. J., Gonçalves da Silva, A., Valcanis, M., Ballard, S. A., Seemann, T., Jennison, A. V., et al. (2019). Emergence and divergence of major lineages of Shiga-toxin-producing Escherichia coli in Australia. Microb. Genom. 5:e000268. doi: $10.1099 /$ mgen. 0.000268 
Kotloff, K. L., Nataro, J. P., Blackwelder, W. C., Nasrin, D., Farag, T. H., Panchalingam, S., et al. (2013). Burden and aetiology of diarrhoeal disease in infants and young children in developing countries (the Global Enteric Multicenter Study, GEMS): a prospective, case-control study. Lancet 382, 209222. doi: 10.1016/S0140-6736(13)60844-2

Kunkel, S. L., and Robertson, D. C. (1979). Purification and chemical characterization of the heat-labile enterotoxin produced by enterotoxigenic Escherichia coli. Infect. Immun. 25, 586-596. doi: 10.1128/IAI.25.2.586-596. 1979

Levine, M. M., Berquist, E. J., Nalin, D. R., Waterman, D. H., Hornick, R. B., Young, C. R., et al. (1978). Escherichia coli strains that cause diarrhoea but do not produce heat-labile or heat-stable enterotoxins and are non-invasive. Lancet 1 , 1119-1122. doi: 10.1016/s0140-6736(78)90299-4

Lindahl, M., and Wadström, T. (1986). Binding to erythrocyte membrane glycoproteins and carbohydrate specificity of F41 fimbriae of enterotoxigenic Escherichia coli. FEMS Microbiol. Lett. 34, 297-300. doi: 10.1111/j.1574-6968. 1986.tb01424.x

Liu, J. K., Wei, C. H., Hou, X. L., and Yu, L. Y. (2014). Passive protection of mice pups through oral or intranasal immunization of dams with recombinant Lactobacillus casei vaccine against ETEC F41. Res. Vet. Sci. 96, 283-287. doi: 10.1016/j.rvsc.2014.01.010

Luppi, A. (2017). Swine enteric colibacillosis: diagnosis, therapy and antimicrobial resistance. Porcine Health Manag. 3:16. doi: 10.1186/s40813-017-0063-4

Miles, A. A., Misra, S. S., and Irwin, J. O. (1938). The estimation of the bactericidal power of the blood. J. Hyg. (Lond). 38, 732-749. doi: 10.1017/ s002217240001158x

Newsome, P. M., Burgess, M. N., Burgess, M. R., Coney, K. A., Goddard, M. E., and Morris, J. A. (1987). A model of acute infectious neonatal diarrhoea. J. Med. Microbiol. 23, 19-28. doi: 10.1099/00222615-23-1-19

Qadri, F., Svennerholm, A. M., Faruque, A. S., and Sack, R. B. (2005). Enterotoxigenic Escherichia coli in developing countries: epidemiology, microbiology, clinical features, treatment, and prevention. Clin. Microbiol. Rev. 18, 465-483. doi: 10.1128/CMR.18.3.465-483.2005

Robins-Browne, R. M., and Levine, M. M. (1981). Effect of chlorpromazine on intestinal secretion mediated by Escherichia coli heat-stable enterotoxin and 8-Br-cyclic GMP in infant mice. Gastroenterology 80, 321-326. doi: 10.1016/ 0016-5085(81)90721-6
Schulz, S., Lopez, M. J., Kuhn, M., and Garbers, D. L. (1997). Disruption of the guanylyl cyclase- $C$ gene leads to a paradoxical phenotype of viable but heatstable enterotoxin-resistant mice. J. Clin. Invest. 100, 1590-1595. doi: 10.1172/ JCI119683

Smith, H. W., and Halls, S. (1967). Observations by the ligated intestinal segment and oral inoculation methods on Escherichia coli infections in pigs, calves, lambs and rabbits. J. Pathol. Bacteriol. 93, 499-529. doi: 10.1002/path.170093 0211

Smith, H. W., and Linggood, M. A. (1971). Observations on the pathogenic properties of the K88, Hly and Ent plasmids of Escherichia coli with particular reference to porcine diarrhoea. J. Med. Microbiol. 4, 467-485. doi: 10.1099/ 00222615-4-4-467

Swenson, E. S., Mann, E. A., Jump, M. L., Witte, D. P., and Giannella, R. A. (1996). The guanylin/STa receptor is expressed in crypts and apical epithelium throughout the mouse intestine. Biochem. Biophys. Res. Commun. 225, 10091014. doi: 10.1006/bbrc.1996.1286

van Zijderveld, F. G., van Zijderveld-van Bemmel, A. M., and Bakker, D. (1998). The F41 adhesin of enterotoxigenic Escherichia coli: inhibition of adhesion by monoclonal antibodies. Vet. Q. 20(Suppl 3), S73-S78. doi: 10.1080/01652176. 1998.9694974

Vial, P. A., Mathewson, J. J., Guers, L., Levine, M. M., and DuPont, H. L. (1990). Comparison of two assay methods for patterns of adherence to HEp-2 cells of Escherichia coli from patients with diarrhea. J. Clin. Microbiol. 28, 882-885. doi: 10.1128/JCM.28.5.882-885. 1990

Conflict of Interest: The authors declare that the research was conducted in the absence of any commercial or financial relationships that could be construed as a potential conflict of interest.

Copyright (c) 2021 Carroll, Hocking, Azzopardi, Praszkier, Bennett-Wood, Almeida, Ingle, Baines, Tauschek and Robins-Browne. This is an open-access article distributed under the terms of the Creative Commons Attribution License (CC BY). The use, distribution or reproduction in other forums is permitted, provided the original author(s) and the copyright owner(s) are credited and that the original publication in this journal is cited, in accordance with accepted academic practice. No use, distribution or reproduction is permitted which does not comply with these terms. 